\title{
In Conversation with Sir William Trethowan: Part II
}

The following is the second part of Brian Barraclough's interview with Sir William Trethowan. Part I appeared in the February Bulletin.

BMB After you left Australia you came back, to Birmingham. How did that come about?

WHT In 1961 I went to Montreal to the International Congress of Psychiatry. Since my fare was paid, not by the University of Sydney I might add, I decided that as I had not been to England for six years and had a few relatives remaining it was time I looked in on them. So I decided to go right round the world. Doing better than Phileas Fogg, I went round in 23 days, including spending a week in England. Birmingham were looking for someone to fill their first Chair of Clinical Psychiatry. I was invited to meet the Dean, the late Professor Pon d'Abreu. He showed me round the hospital. He seemed to be interested in me, but said the Vice-Chancellor wasn't there, and could I come back on Saturday. D'Abreu asked me to stay with him at his house in Coughton Court. He, the Professor of Medicine and the Vice-Chancellor ofiered me the Chair over the port. Now that's a civilized way to get a job.

BMB What was psychiatry like in Birmingham then?

WHT Such teaching as there was, was in the hands of two or three part-time consultants. There was a Chair in Experimental Psychiatry which was really neuropharmacology which had been held by Joel Elkes, now Professor at Johns Hopkins.

BMB Was that a personal appointment or an established Chair?

WHT I believe Elkes's Chair was established. However, Birmingham is a conservative place so that when the University first decided to embrace psychiatry it wanted to make sure it was 'respectable'. Respectable psychiatry was to do with neuropharmacology in those days - maybe it still is! Elkes went to America about three years before I came, leaving the Chair to Philip Bradley whose Department has since become Preclinical Pharmacology.

BMB There is no longer a Chair of Experimental Psychiatry?

WHT No. Mine was the firat Chair of Clinical Psychiatry.

BMB And how did you find things when you got here?

WHT I was given a lot of promises. I was told there were funds and facilities to set-up an equivalent of the Maudsley in the Midlands. Of course it never materialized. In fact I never expected it to. But I was promised more facilities than I ever actually received. Within a year I had a small allotment of beds and I finished, after 21 years, with the same small allotment of beds. I looked at the existing facilities to see how they could be exploited. We set up a clinical tutors' scheme in the West Midlands, which was the first to be established and which was later widely copied. Every mental hospital had a clinical tutor with an official University appointment. Also a scheme for rotating senior registrars, which was so successful we were allowed more senior registrars in psychiatry than any Region outside London. I think exploiting existing facilities is more likely to pay dividends than trying to set up something new and waiting hopelessly for money. These things depend on money. The National Health Service is in recession at present and things aren't likely to improve.

BMB What about your own department?

WHT The department was always small.

BMB What was it when you arrived?

WHT Just me! I insisted on a first assistant and senior lecturer. Nobody can operate in isolation if only because of clinical commitments. When I retired last year we had two senior lecturers in adult psychiatry, one senior lecturer in child psychiatry, a lecturer in psychiatry and two in clinical psychology.

BMB Turning to undergraduate teaching, would you like to say something about objectives in training undergraduates?

WHT I believe that the most important thing a university department of psychiatry can do is to train undergraduates, it is more important than postgraduate teaching. When I came to Birmingham in 1962, undergraduates received four weeks of psychiatry, optional. Fifty per cent of them elected to do it. Soon the four weeks were made compulsory and increased to six, eight and finally ten weeks, and psychiatry was made a final year subject. In Birmingham we place great emphasis on continuous assessment. The final year comprises five ten-week periods: senior medicine, senior surgery, obstetrics, paediatrics and psychiatry. Batches of students come for ten weeks, full-time. At the end of the ten-week period they are examined. If they pass they are finally through as far as that subject is concerned. If they fail or are of distinction standard they have another examination in June. The advantage? When a student is doing psychiatry or any other final year subject, he is doing that and nothing else. He is not swotting for a major final examination. In ten weeks you can teach them a lot. The time to inculcate an interest in psychiatry is the undergraduate level. In a recent study ${ }^{1}$ of interests shown by medical students on qualification rating various specialties, Birmingham in 1961-5 was fifteenth for students taking up poychiatry. In 1971-5, Birmingham was fourth. I am told it may 
now be even higher. I am very proud of that. Also, since we have been teaching more psychiatry, young general practitioners and young house officers are picking up psychiatric patients and telling their chiefs: 'You have a psychiatric problem here and ought to refer it.' The letters we get from general practitioners are also much more insightful and more perceptive of psychiatric problems.

BMB What do you aim to teach undergraduates?

WHT An overview of the range of psychiatric problems they are likely to encounter in general practice or in a general hospital or in some other kind of practice.

BMB By lectures?

WHT I gave up lecturing years ago. That's not absolutely true. I do give the occasional (usually guest) lecture. But in teaching undergraduates we tend to concentrate on small group teaching - seminar teaching.

BMB Rather than case demonstrations?

WHT Using patients or video-tapes - to teach awareness of psychiatric problems and to recognize those patients who need referral to a psychiatrist, and not to be contemptuous of psychiatric patients like people in my student days used to be. The next thing is how to interview psychiatric patients. How do you get the information. I used to be appalled at the inability of the average doctor to get information from patients and understand it, even how to listen properly. These skills apply to all medical practice. How to do it quickly without letting the patient waste your time, or wasting your own time. Simple psychiatric conditions can and are being treated adequately by general practitioners and non-psychiatrists. There will never be enough psychiatrists to cope with psychiatric patients. Paradoxically, the more we teach undergraduates, the more difficult our clinical problems become.

BMB You were one of the first departments to take up television teaching?

WHT I think we were the first department in this country to use a video-tape recorder. There was one at the Maudsley and one in Edinburgh, but we got ours unpacked first. It was a black and white reel to reeland what a thing that was, I can remember the trouble we had.

BMB Was it any use?

WHT It made an immediate impact. We progressed to the more sophisticated studio we have now, with cameras and colour. The advantage of video-tapes was to see what a psychiatrist does with his patient. At the Maudsley many years ago as a young registrar there was this mysterious thing called psychotherapy. We all had to do it but nobody ever taught us how; it was done behind closed doors and we wondered what it was that was going on. Now you can see it all on a TV screen.
BMB What do you use it for in teaching undergraduates?

WHT Teaching interviewing, so students can see themselves interviewing and for showing interesting cases. In a small unit there is always a shortage of patients and a video-recorder gives you a demonstration library of cases of mania, manic depressive psychosis, schizophrenia and so on.

BMB That's expensive on staff time.

WHT It is. Luckily, members of my staff, particularly Tim Betts, were keen. In recent years I dropped out because I felt they did it better. We also experimented with video as an examination medium and the College paid for a research fellow. We concluded it was best used as a talking point. Show a little bit of a video-tape and ask the candidate to comment, rather like a short case in a medical exam.

BMB With such a small department, how did you get on in research? Do you feel that undergraduate departments should do research?

WHT I felt it was my duty not so much to do research myself, but to find funds and facilities for younger members of the department to do research. This is a professor's job. After all they are making their careers; it doesn't really matter to me whether I do any more research, or at least it didn't over the last few years. My reputation is already made-or broken.

BMB What happened in your department?

WHT I never believed in directing research. People should find their own research subjects and if they are good I encourage them. I never believed one should say, 'Why don't you look into this?' I am rather against that. People must generate their own research ideas. Once they have them and say, 'Do you think this is a good idea?', then you are at liberty to criticize or say, 'Yes I do' or 'It's been done before, I don't think you will get much joy from it', or something of that kind. But I don't believe it is my duty to tell other people what they should research.

BMB I remember one paper ${ }^{2}$ from your department about coal gas and the suicide rate in Birmingham. How did that come to be done?

WHT The Coroner wrote and said suicide is dropping considerably and I don't know the reason for it. So Christine Hassall, senior research fellow in my department, and I looked at the coroner's record cards. Sure enough the number of suicides in Birmingham had dropped in the most extraordinary way. There seemed no reason for it. So I said to Christine, 'Let's go about it in the simplest way we can'. The Coroner kept cards which showed the name, sex, age of the person, the verdict and the method of suicide. So I said, 'We'll take these first' and divided them into active methods (cutting, selfhanging, jumping in the river, jumping in front of 
lorries), completely passive (taking pills of various kinds, overdoses) and an inbetween group, coal gas, a sort of halfway between active and passive. We found that violent methods of suicide or active measures had risen slightly in males, while the number of passive suicides with pills had remained constant. But coal gas ones had greatly fallen. Birmingham was not on North Sea gas. So I wrote to the secretary of the Gas Board who wrote back that they had detoxified the ordinary town gas from about 20 per cent carbon monoxide to 2.5 per cent. He was also kind enough to enclose the figures for industrial accidents due to coal gas which followed a similar curve to suicides. This finding has sometimes been passionately disputed at conferences I have attended, but it seems to me to be unchallengeable. The figures are absolutely plain.

BMB Sainsbury doesn't believe that the change in the toxicity of gas has reduced the national rates.

WHT What does he believe it is due to?

BMB He believes it is partly due to an improvement in treating depressive illness with antidepressant drugs.

WHT I don't think there is much evidence of that, otherwise the number of suicides with pills would have dropped over this period, and what's more the decline in the number of coal gas suicides begins precisely at the point that it was detoxified. It seems to be inescapable.

BMB I agree with you. And the national rate has flattened out as the coal gas detoxification programme has been completed.

Can we turn to your books? Did you co-author Anderson and Trethowan or just take it over?

WHT I co-authored the second edition.

BMB Did Anderson take it over from Dawson?

WHT Originally it was Aids to Psychiatry by W. S. Dawson. Anderson took it over and wrote the first edition-considerably different from Dawson's, completely re-written; for the second edition I became his co-author. I wrote about a third of it and re-wrote a lot of what he had written. For the third edition I became the principal author and he the sleeping partner. Anderson, whose psychiatry was German based, also wrote English in a Teutonic style. His publishers said to me, 'For goodness sake, put some paragraphs in' (some of his paragraphs lasted several pages)—so I did. The book is more readable. The fourth edition ${ }^{3}$ I wrote completely by myself as he had died. The fifth edition, due to come out shortly, is being re-written with the help of Andrew Sims who, of course, shares my phenomenological interests. He can take it over for the sixth edition. The book has a life, it sells well.

BMB Profitable?

WHT Not after the taxman. Over 3,000 copies a year are sold now, almost 50 per cent abroad and the abroad sales are increasing.

BMB What do you aim to do in the book?

WHT To give an intelligible account of psychiatry, its possibilities, its limitations, in such a way that undergraduates and general practitioners will take an interest in the subject and young graduates who wish to learn more can profit from it. The book is not intended for those training for psychiatry, although a trainee who knows it should get through the Membership.

BMB Your other book is Uncommon Psychiatric Syndromes?4 How did you come to write that?

WHT I have always been interested in the byways of psychiatry and so has David Enoch, my co-author. He wrote papers on the Capgras syndrome and the Othello syndrome. I was interested in the other topics. We thought we would write a book on the more colourful aspects of psychiatry-nearly all of them paranoid states, incidentally. We collected historical and literary material as well as clinical, which is the point of the book, not just unadorned clinical description. We wrote it for our own entertainment and hopefully for that of others. The second edition has certainly gone much better than the first, which was over-priced. There is also a Japanese edition.

BMB You came to Birmingham in 1962 and you were appointed Dean of the Medical School in 1968. It is unusual, I think, for the Professor of Psychiatry to become Dean.

WHT I was the first Professor of Psychiatry, south of the border, to become Dean of a Medical School. There was one in Scotland, Malcolm Millar, Dean of Aberdeen.

BMB And only?

WHT For a time. Of course others since-Neil Kessel in Manchester, for example, and Arthur Crisp at St George's, representing London University.

BMB How do you think being Dean affected the development of psychiatry in the University. Were you able to give it a special force?

WHT No. One has to bend over backwards not to favour one's own department, to be neutral and be seen to be neutral. However, I did get another senior lecturer out of it - I had to because I didn't wish the department to fall to pieces. The effect on the Department was on the negative side. Work that I would have done as Professor fell on the shoulders of others.

BMB Looking from the vantage point of Dean, did you think the Department of Psychiatry was receiving a fair crack of the whip?

WHT Well I never thought the Department of Psychiatry had a fair crack of the whip during my time in Birmingham. I was promised facilities, a new unit for psychiatry, none of which ever came to pass. I am 
not saying that Psychiatry fared worse than other departments, but as usual, medicine and surgery reign supreme. In short, I don't think being Dean brought any advantage to the Department of Psychiatry.

BMB I suppose having the Professor as Dean was a distinction for the Department-it's unusual.

WHT It is unusual-I was very complimented. I said to the Vice-Chancellor, 'Why do you want me to be Dean?'. He said, 'I think it is a good thing to have a psychiatrist as Dean - they understand other people's motives!'

BMB Like Anthony Clare, I suppose. Do you think being a psychiatrist did help though? Did the ViceChancellor's joke turn out to be true?

WHT Yes, I think so. Psychiatrists do understand other people's motives-we are trained to do so, but in respect primarily of mental patients. One has to be careful about bringing too much psychiatric understanding into dealings with people who are not, at least overtly, suffering from psychiatric illness.

BMB Did you find the fact of being a psychiatrist and Dean led to your being treated by your admin colleagues as more respectable?

WHT No. I must have been regarded as respectable to be made Dean.

BMB It's a democratic decision?

WHT No it isn't entirely. The Dean is not elected at Birmingham. The Medical School existed long before the rest of the University and the Dean of the Medical School is appointed by the Council of the University on the recommendation of the Vice-Chancellor, who does, however, take soundings. Deans of other faculties are elected by their faculties.

BMB Can we turn to the Royal College of Psychiatrists? What are your views about the College being founded?

WHT In the early days I was against its foundation. Meetings took place at the Royal Society of Medicine. I, with other colleagues, opposed the foundation for a time.

BMB Why did you oppose it?

WHT Because I felt we were multiplying Colleges needlessly. I felt there should be a closer affiliation between psychiatry and the Royal College of Physicians and was against the creation of yet another diploma which would inevitably follow upon the foundation of the College.

BMB Who were the others who shared your view?

WHT Sir Denis Hill felt the same way, and a lot of the senior people in psychiatry; also Desmond Curran, if I remember rightly.

BMB If the Royal College of Physicians had been more accommodating, would an affiliation have been possible?

WHT Yes. It is a big 'if though, because the Royal College of Physicians has never shown itself to be particularly accommodating.

BMB Not since 1519?

WHT No. I have great respect for the Royal College of Physicians, but if there is blame to be laid anywhere I would put it at their feet- the blame for the foundation of the Royal College of Psychiatrists and other Colleges as well. Some specialties had to form themselves into Colleges to shake off the shackles of the Royal College of Physicians.

BMB Do you feel the Royal College of Surgeons has been more accommodating in the way they have coped with, say, the dentists?

WHT On the surface, at least, yes. They are less involved and less threatened. The surgeons are a race apart. They were always a race apart, having, to a certain extent, to defend themselves against the physicians, although that goes much further back into history.

Those of us who opposed the formation of the Royal College of Psychiatrists felt bound to give it our support when it was shown that the majority wanted it.

BMB Did you play a part in the formation of the Charterall those long negotiations?

WHT No, I played no part in that at all.

BMB But when the College was founded you became the first Chief Examiner?

WHT I became the first Chief Examiner, for my sins!

BMB Since you have mentioned sins, what were they in relation to that exam?

WHT First of all, having an exam at all. You could say I connived, yet we are not at a stage where we can get away from exams.

BMB What would you have instead?

WHT There is no substitute at the present time. One can't do without an exam, yet I am always hesitant to add another to the fate of the young postgraduate. At a time when a young man should be doing research, he is faced with an exam. But what's the alternative? It blocks his research; the College tried a research option without success.

BMB Why wasn't it a success? I did the Maudsley DPM. The compulsory research dissertation had a marked effect on my development and career, as I think it had with others like myself.

WHT It is difficult to compare the Maudsley DPM, an internal examination which the training was geared to, with the Membership, and it was compulsory research. The College one was not.

BMB No, but why wasn't it?

WHT One reason is that most people examined for the College diploma never write a research paper in their lives and are not capable of doing so. I am sure you know that's true.

BMB I am not sure I do agree. I believed it was more 
because of the influence of the Privy Council and the Royal College of Physicians through the Privy Council.

WHT If that's so, I have no direct knowledge of it.

BMB Anyway you became Chief Examiner. Why did you become Chief Examiner? What was the purpose?

WHT I can't remember why I became Chief Examiner. I suppose I was fool enough to volunteer. I got landed with it for seven years and by that time I had had enough.

BMB What did you try to do through the examination? The examination determined what young doctors did for some three years of their training.

WHT The exam was a test of knowledge at a half-way point in a young man's career which would determine whether it was worth his going on training.

BMB How did you decide what the test should be?

WHT We had a committee-of course-to which people brought varying degrees of experience of examinations. How else can one do it? And out of the deliberations of this committee, the exam took the form which it more or less is at present-a multiplechoice exam, a clinical and vivas. The College built in from the beginning an examination of the exam in statistical terms, which was far-sighted. Christine Hassall, senior research fellow in my department, produced statistics to monitor the exam. The statistics were interesting. They told us about the abilities of candidates from different parts of the country and allowed inferences to be made about the quality of their training. The north of England candidates were less successful than the south of England candidates and overseas candidates were less successful than home candidates. Of course the exam was geared to British candidates. It also showed, although we didn't publish this, some interesting things about examiners.

BMB What did it show?

WHT Tremendous variation in the ability of the examiners, and how some examiners were probably unqualified to examine.

BMB Were they removed?

WHT No, possibly because the statistics did not refer to them as individuals. The most interesting thing which I think the figures show incontrovertibly is that the clinical exam and the multiple-choice tests are the only worthwhile parts of the exam. Whatever rude things people say about multiple-choice tests, they are the best sort of screen. I am appalled at the extraordinary differentials in the essay examiners' marking. When the College responded to this by producing model answers, it seemed not to make the slightest difference. Either the examiners didn't read the model answers, or, if they did, they disagreed with them or for some other reason, it made no differ- ence-the discrepancies were just as bad. Although multiple-choice questions are tedious things and people say they only test the ability to do multiplechoice questions, they seem to correlate extremely highly with clinical ability. It makes you think.

BMB You have remained in the College even though you have stopped being Chief Examiner?

WHT Oh yes! I have not held any office for some time, that's because of increasing age. You can only do so much.

BMB What do you think about the College at the present time?

WHT It is thriving. I was opposed to its formation, but I am happy about the way it has progressed. But I am much more a University than a College man.

BMB Is there much difference?

WHT Oh yes - the great advantage of a University post, something I value greatly, is working in close association with people of varying interests, whereas the Royal College of Psychiatrists is virtually only concerned with psychiatry. It is the same in all Colleges. In universities there is a cross-fertilization of different disciplines. It makes life much more interesting.

BMB You were the Chairman of a DHSS committee which considered how psychologists were to be recruited and employed in the National Health Service. There was a report ${ }^{5}$ which caused a bit of a stir when it first came out.

WHT Now this is interesting because this was a sub-committee of the Standing Mental Health Advisory Committee at the Department of Health. I was Chairman of the Standing Mental Health Advisory Committee as successor to Denis Hill. During the time I was Chairman this sub-committee was set up to consider the role of psychologists in the Health Service and found itself without a parent because the Standing Mental Health Advisory Committee got quangoed and abolished. The Department had an economy drive and decided to get rid of lots and lots of committees including the Central Health Service Council. The sub-committee continued in being.

BMB I suppose this sub-committee came into being because of the emergence of behaviour therapy as an effective treatment?

WHT Partly, but also because the role of the clinical psychologist in the National Health Service was under scrutiny. Behaviour therapy stimulated this further, but it was ripe anyway. This report has been favourably received by psychologists, if not by psychiatrists.

BMB What do you think it did for the clinical psychologist?

WHT The main recommendation was the setting up of an organized Area-based service and a structured career for clinical psychologists. In 1974, the National Health Service underwent an upheaval and Areas and 
Districts were born. A lot of people, particularly the paramedical people, felt themselves to be in limbo in this administrative structure.

BMB A proposal was made in that committee that psychologists should only accept patients who had first of all been vetted by psychiatrists. That was removed, wasn't it, later?

WHT I don't think it was ever officially removed, not as far as I can recollect.

BMB In practice, psychologists take referrals from anywhere?

WHT Yes, but this was certainly not the recommendation made by my committee.

BMB What did your committee recommend then?

WHT Our committee was quite firm, and the psychologists on the committee themselves agreed, that medical responsibility as such should not be taken by psychologists and all cases should be screened by a psychiatrist, or other doctor before referral to a psychologist.

BMB If we can turn now to the Worcester project.

WHT The Worcester project was set up to demonstrate that sufficient general hospital facilities and community services could cope with all the work which would normally be done by a mental hospital. The DHSS chose Powick Hospital, near Worcester, for this purpose because they felt Worcestershire was an area which represented both urban and rural mental health problems in reasonable proportions. The DHSS came to me with a huge document and an offer of considerable facilities for a research project. These were on a grandiose scale. I was worried because I felt they were providing facilities to see what they wanted to prove, proved. I favoured the development because general hospital psychiatry, given the facilities, represents a turn away from the traditional County Asylum approach. At the same time I am not sure that the day of the mental hospital is over. But the DHSS research project contained a strong bias towards proving what they wanted to see proved. I said so and went so far as to turn down some of the facilities offered. Instead I said I would do some limited research which is what happened.

They then set up a co-ordinating committee with me as Chairman, with Community Medical Officers, Directors of Social Work of the County and the town of Worcester, psychiatrists, general practitioners and others concerned including officials from the Department. We held quarterly meetings to examine what was going on. Over a long period, I now forget how many years, what had been hoped for has largely come to pass. We have seen the rundown of Powick and the provision of new psychiatric facilities at Newton and Kidderminster, which are the two main towns in Worcestershire, together with the develop- ment of community facilities, day hospitals and things of this kind all envisaged in the original project. The project has been not starved exactly, but pinched for money. At one time when things got critical, we had a very stormy meeting because it looked as if the whole project was going to founder because of a financial squeeze. I went to London and interviewed the CMO and Sir Patrick Nairne, who was the chief civil servant in the Department, saying, 'If you want this project to go on you will have to find the money', and they did. The results, however, have not been an unqualified success. The geriatric problem held us up. There are still geriatric patients at Powick and I don't know how they are going to be disposed of. There has been some talk of turning Powick into a geriatric hospital which, to a certain extent, nullifies the object of the exercise. The main thing we hoped to do was to close the wards and pull the hospital down. However, the two general hospitals and community services do seem to be containing Worcestershire's mentally ill.

BMB I see you have a Hong Kong Doctorate.

WHT In about 1975 I was asked to become Chairman of the Medical Academic Advisory Committee to set up an entirely new Medical School at the Chinese University of Hong Kong in the New Territories. I thought this a most interesting project and accepted. There was only one medical school in Hong Kong at Hong Kong University which was not producing enough medical graduates. Our first medical undergraduates are now entering their clinical years and will graduate in 1985 . It's been fun setting up a new medical school from scratch. The place has got plenty of money to do it, and lots of material, it makes a change from what goes on in this country.

BMB What will happen to it in 1997 ?

WHT I don't know, your guess is as good as mine. They gave me an Honorary Doctorate of Science for my services to the Chinese University.

BMB What do you think about distinction awards? Every year the British Medical Journal publish an analysis of distinction awards, paying attention to the way in which psychiatrists of various kinds are discriminated against.

WHT Having seen the distinction award system from inside - as adviser in mental health both nationally and at a regional level-my view is it is probably about as fair as circumstances allow it to be. This is not to say that there is no discrimination against specialties. I would agree that probably psychiatry is not as well represented as it should be, but this is difficult to judge. People in the centre of things, in active hospitals, are advantaged by the fact that they are under the eye of their colleagues, and after all it is their colleagues who put them up for distinction 
awards.

BMB What are distinction awards, what is their purpose? Are they to reward research ability, academic distinction, teaching ability or are they for people who work hard for the benefit of the National Health Service?

WHT There has recently been a change. Originally they were to reward academic distinction, research ability and teaching ability but there has recently been a change at least in relation to $C$ awards, towards rewarding long and arduous service, often in places in which people would not care to work, to my mind quite rightly. I mean if a man writes lots of papers and is a well-known teacher, he is in the public eye and one knows first-hand what his abilities are and can form a judgement on whether he should be rewarded. But the man in some backward area, slogging away, doing a good job, his services isolated from his colleagues-the value of his work is more difficult to judge. This is the snag with distinction awards.

BMB There has been a problem in Birmingham with inpatient suicides?

WHT You would think so by the publicity. In fact our statistics show that for 2,654 admissions over a period of years our suicide rate was 0.23 per cent ( 6 patients in all). I don't think anyone should complain at that.

BMB But the wards closed.

WHT Oh yes, yes. This was because the coroner decided to hear three cases, which occurred in separate wards and over a period of time, all on one day, thereby exciting the national press, the local press and the horror of the hospital administrators. There was a good deal of hysteria about it.

BMB Would you like to talk about that. I think the local press and their behaviour about local suicides can have a bad effect.

WHT So do I. Most psychiatrists agree that suicide is not completely preventable so that one has to accept a minimum suicide rate in the same way that one has to accept a small proportion of anaesthetic deaths and deaths from surgical operations. Short of chaining patients to the wall, I don't see how you can prevent them. The dramatization by the press is unreasonable. No good comes of it. It damages the image of psychiatry, gives pain to the relatives of the deceased and hampers those of us working towards a more liberal approach to the care of the mentally ill.

REPERENCES

'BrooK, P. (1983) Who's for psychiatry? United Kingdom medical schools and career choice of psychiatry, 1961-75. British Journal of Psychiatry, 142, 361-5.

${ }^{2}$ Hassall, C. \& TREThOWAN, W. H. (1972) Suicide in Birmingham. British Medical Journal, 1, 717-8.

${ }^{3}$ Trethowan, W. H. (1979) Psychiatry, 4th Edition. London: Baillière Tindall.

${ }^{4}$ ENOCH, M. D. \& TrethowaN, W. H. (1979) Uncommon Psychiatric Syndromes, 2nd Ed. Bristol: John Wright.

'Department of Health and Social Securtry (1977) The Role of Psychologists in the Health Service. HC (77) 14. London: HMSO.

\section{Postgraduate Training in Behavioural Psychotherapy}

The Association of University Teachers of Psychiatry recognizes the recommendation of the Royal College of Psychiatrists (1971) that experience in behavioural psychotherapy should be an integral part of the training of psychiatrists. To help reduce the shortage of trainers in this field the AUTP, with the Institute of Psychiatry, runs a course to increase available training resources. This course is mainly intended for consultants and senior registrars and those of equivalent status, including specialist psychotherapists, but a limited number of other places may be available.

The course will begin with a two-day workshop on 27 and 28 September 1984. This will include the following components: theoretical background, demonstration of treatments and participant practice in small groups. After the workshop participants will be asked to undertake behavioural treatment of their own patients in their own centres, and later also to supervise other trainces. Participants will be supervised in small groups at monthly intervals in half-day sessions over the following academic year.

The course is organized on lines which qualify for local funding assistance under Study Leave Regulations of the BPMF. The cost of the combined workshop and monthly supervision over the following academic year would be $£ 219$.

Applicants should write, including a brief curriculum vitae, to Professor Isaac Marks at the Institute of Psychiatry, De Crespignỳ Park, Denmark Hill, London SE5 8AF, where the course will be held. 